\title{
Attainable Moment Set and Actuation Time of a Bio-Inspired Rotating Empennage
}

\author{
Christian R. Bolander* and Douglas F. Hunsaker ${ }^{\dagger}$ \\ Utah State University, Logan, UT, 84321 \\ David Myszka ${ }^{\dagger}$ \\ University of Dayton \\ James J. Joo $§$ \\ U.S. Air Force Research Laboratory, Wright-Patterson Air Force Base, Ohio, 45433-7402
}

\begin{abstract}
Future tactical aircraft will likely demonstrate improvements in efficiency, weight, and control by implementing bio-inspired control systems. This work analyzes a novel control system for a fighter aircraft inspired by the function of - and the degrees of freedom available in - a bird's tail. The control system is introduced to an existing fighter aircraft design by removing the vertical tail and allowing the horizontal tail surfaces to rotate about the roll axis. Using a low-fidelity aerodynamic model, an analysis on the available controlling moments and actuation speeds of the baseline aircraft is compared to that of the bio-inspired rotating empennage design. The results of this analysis at a takeoff and approach flight condition indicate that the bio-inspired tail design is able to improve upon the baseline in terms of control power available for yaw by up to $170 \%$, while also improving the actuation speed by about 450 milliseconds for moments about the pitch axis. The bio-inspired design is shown to have actuation times that are up to 600 milliseconds slower for generating yawing moments and a reduced roll control contribution from the tail in certain moment combinations. The impacts of these issues on control will need to be determined with analysis at additional flight conditions and a flight dynamics analysis.
\end{abstract}

\section{Nomenclature}

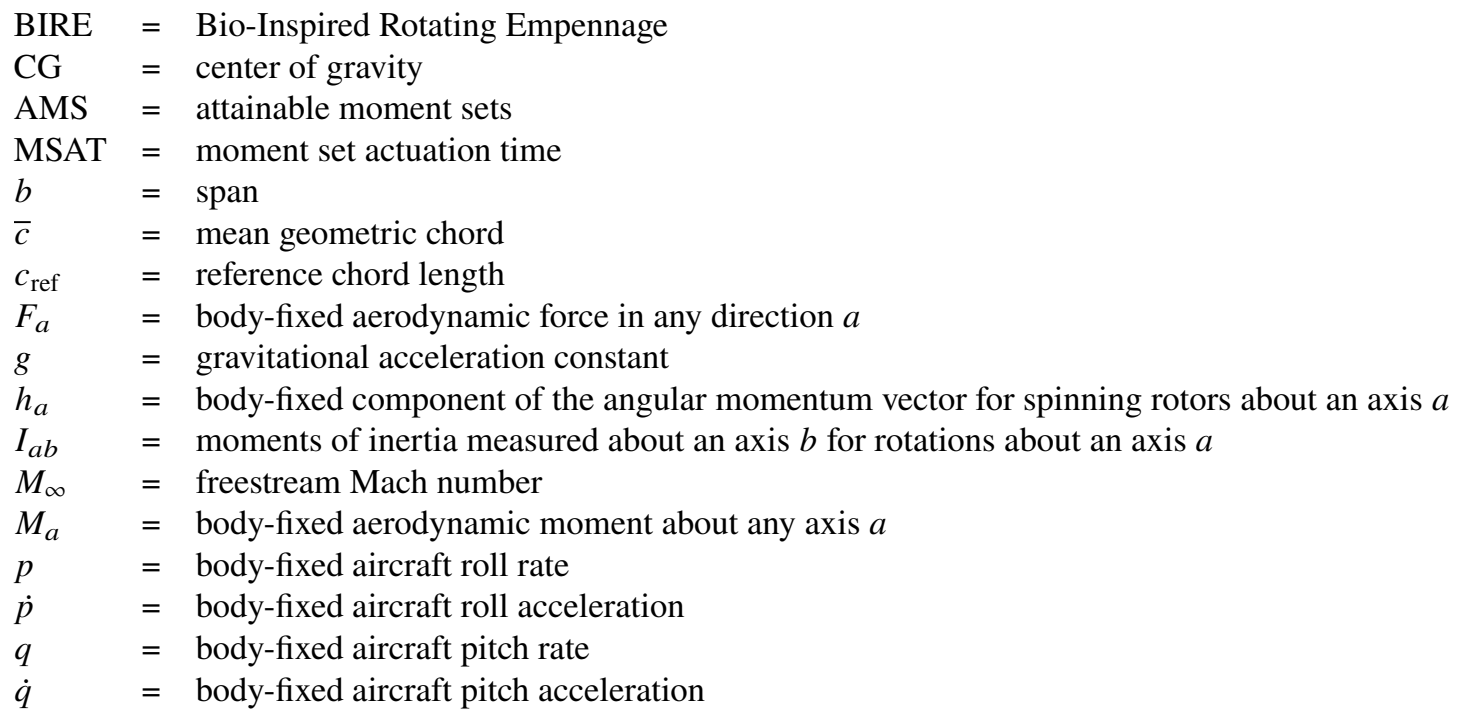

*PhD Candidate, Mechanical and Aerospace Engineering, 4130 Old Main Hill, AIAA Student Member

$\dagger$ Assistant Professor, Mechanical and Aerospace Engineering, 4130 Old Main Hill, AIAA Senior Member

Professor, Department of Mechanical and Aerospace Engineering

${ }^{\S}$ Senior Research Mechanical Engineer, AFRL/RQVS, 2790 D St., AIAA Senior Member 


$\begin{array}{ll}r & =\text { body-fixed aircraft yaw rate } \\ \dot{r} & =\text { body-fixed aircraft yaw acceleration } \\ R_{A} & =\text { aspect ratio } \\ R_{T} & =\text { taper ratio } \\ S & =\text { planform area } \\ u & =\text { body-fixed aircraft velocity in the } x \text {-direction } \\ \dot{u} & =\text { body-fixed aircraft acceleration in the } x \text {-direction } \\ v & =\text { body-fixed aircraft velocity in the } y \text {-direction } \\ \dot{v} & =\text { body-fixed aircraft acceleration in the } y \text {-direction } \\ w & =\text { body-fixed aircraft velocity in the } z \text {-direction } \\ \dot{w} & =\text { body-fixed aircraft acceleration in the } z \text {-direction } \\ W & =\text { aircraft gross weight } \\ \hat{x}_{\mathrm{cg}} & =\text { dimensional reference location of the aircraft CG } \\ \alpha & =\text { angle of attack } \\ \beta & =\text { sideslip angle } \\ \Gamma & =\text { dihedral angle } \\ \delta_{a} & =\text { antisymmetric differential tail deflection } \\ \delta_{B} & =\text { BIRE empennage rotation angle } \\ \delta_{e} & =\text { symmetric stabilator deflection } \\ \delta_{h} & =\text { stabilator tail deflection saturation angle } \\ \delta_{r} & =\text { rudder deflection angle for the baseline aircraft } \\ \theta & =\text { elevation angle } \\ \Lambda_{L E} & =\text { leading-edge sweep angle } \\ \Lambda & =\text { quarter-chord sweep angle } \\ \phi & =\text { bank angle }\end{array}$

\section{Introduction}

Efforts to produce the next-generation tactical aircraft, including concepts released by Northrop Grumman, Lockheed Martin, and Boeing [1] have focused on tailless, flying-wing designs. Since the empennage of an aircraft has been shown to generate a substantial portion of the total drag of the aircraft [2], these flying-wing designs reduce drag when compared to traditional aircraft. Yet, because of reductions in stability from removing the empennage, flying-wing designs often require complex distributions of control actuators, such as combinations of differential thrust, split flaps, and elevons. To mitigate such additional complexity, an aircraft design that removes the vertical tail while keeping the horizontal tail could offer improvements to both range and performance [3] while reducing control system complexity compared to a flying-wing design. To evaluate the benefits to aerodynamic control that such a design may offer, this paper evaluates the aerodynamic control characteristics of a concept dubbed the Bio-Inspired Rotating Empennage (BIRE) currently being analyzed at the Air Force Research Laboratory [4].

The BIRE concept is so-named because its design evokes the configuration of natural fliers, such as birds, which fly without a vertical tail and maintain control using non-planar motions of their wings and tail. Several bird species, such as the red kite shown in Fig. 1a, have been observed to rotate their tails about both the pitch and roll axes during flight [5, 6]. Tail rotations about the pitch axis are likely useful as a means of controlling pitch [6-11]. When the tail is held horizontal, these tail deflections are analogous to elevator deflections in a traditional aircraft [8]. Pennycuick [12] proposed that some birds, such as kites, provide active pitch control with their tails through continuously deflections throughout their flight. Rotations of the tail about the roll axis (as in Fig. 1a) may be a means by which birds produce both rolling [7, 8, 13,-19] and yawing moments [8, 13, 20, 21]. Note that these observations do not extend to all bird species and do not completely describe how these morphological changes may be used by birds to control their flight. Nevertheless, the results referenced above justify investigation into a robust two degree-of-freedom control system for the tail of an aircraft that could allow for control in all rotational degrees of freedom. The BIRE design shown in Fig. $1 \mathrm{~b}$ represents precisely such a control system and seeks to emulate the out-of-plane movement of the tail produced by birds such as the red kite, though it is not the first design to do so.

A form of the bio-inspired empennage rotation presented here has been investigated in the past. Both Lockheed Martin [23] and Boeing [24] performed in-depth studies on potential control mechanism designs for tailless aircraft. These studies included a wide range of mechanisms such as a moveable chine or strake, split aileron devices, all-moving 


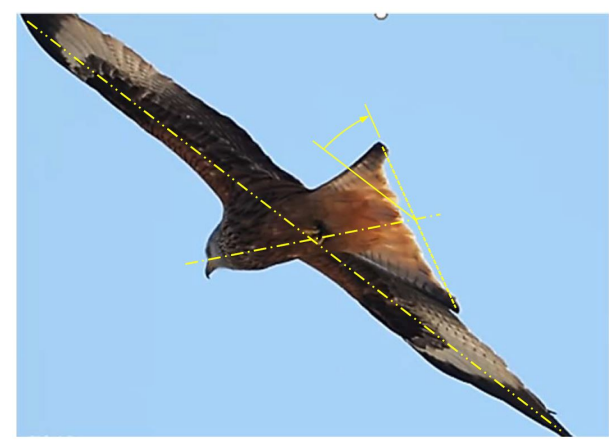

(a) Red kite, adapted from [22]

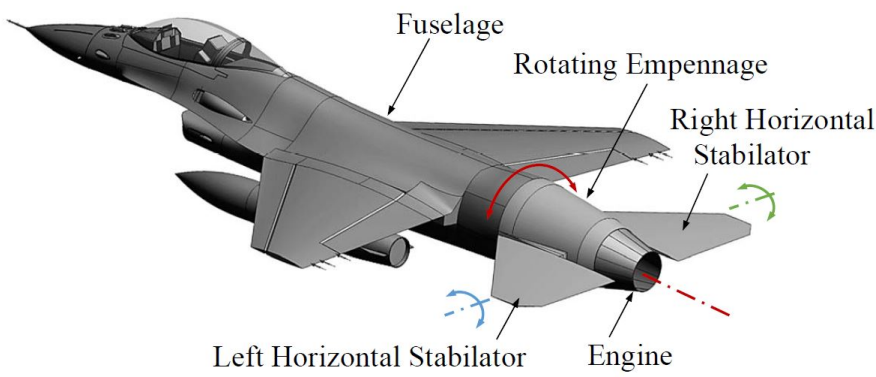

(b) BIRE

Fig. 1 The red kite rotates its tail during flight (a), presumably to provide active lateral control. The BIRE (b) is intended to emulate this movement.

wing tips, differential leading-edge flaps, and a deployable rudder. One control system proposed by Roetman et al. [24] removed the vertical tail and allowed the horizontal stabilizers to change their dihedral angle to provide lateral control and stability. Of all of the mechanisms examined by Roetman et al. [24], they determined that this variable-dihedral horizontal tail design, similar in principle to the BIRE, was the most promising in terms of stability, control, and simplicity of implementation. Roetman et al. [24] found that the design was able to achieve level 1 handling qualities [25, 26] in various flight conditions and chose to recommend its design above the other mechanisms studied. The analysis of this control concept was limited, however, as the dihedral angle was not allowed to change during flight simulation due to limitations on the control law implemented in their study [24].

Another similar design was proposed by Bras et al. [27] that consisted of rotating tail systems with two, three, and four degrees of freedom. The two-degree-of-freedom design consisted of a horizontal tail with the ability to perform solid-body rotations about the roll axis as well as elevator deflections. In this design, the rolling moment was primarily controlled by the ailerons of the main wing. Likewise, the designs with three and four degrees of freedom were able to rotate with a fixed and variable angle between each horizontal tail surface, respectively. The results from an aerodynamic stability analysis of each of these designs indicated that both the two- and four-degree-of-freedom designs were feasible options for providing static and dynamic stability to the aircraft.

The BIRE design that will be analyzed in this work implements a system with three degrees of freedom as shown in Fig. 1b. These degrees of freedom include: rotation of the empennage about the roll axis (1), symmetric deflections of the horizontal tail (2), and antisymmetric deflections of the horizontal tail. The mechanical actuation details of the BIRE concept are explored in another work by Myszka et al. [4] and will not be given here. It has been observed that some birds exhibit an additional degree-of-freedom compared to that shown in the BIRE, by independently "drooping" the left or right portions of the tail [5]. This would correspond to allowing each half of the horizontal tail to rotate about the empennage independently, rather than in a solid-body motion. In spite of the presumed aerodynamic benefits inherent in such a design, the design with three degrees of freedom was selected to create a more tractable mechanical system [4].

The aerodynamic control provided by the three degree-of-freedom BIRE concept can be understood intuitively by considering the total force and moment generated by a traditional empennage. As shown in Fig. 22, a traditional empennage generates individual forces and moments on the horizontal and vertical surfaces, shown in grey, that can be summed together to yield a net force and moment, shown in red. Using a combination of symmetric deflection, antisymmetric deflection, and tail rotation, the BIRE should be able to produce an equivalent net force and moment. Therefore, by leveraging an additional degree-of-freedom to that of a common horizontal tail, the BIRE is able to produce the lateral moments generally created by a vertical tail and rudder with only two aerodynamic lifting surfaces.

Although removing the vertical tail has many potential benefits, including reductions in weight, actuation complexity, and drag, and an increase in the maneuverability of the aircraft, there are several potential challenges with the design that must be considered. Since the vertical tail and rudder on a traditional empennage are primarily responsible for providing lateral stability and yaw control, a key challenge in removing the vertical tail is finding a way to produce adequate lateral control and stability. Additionally, any rotation of the tail to produce lateral moments decreases the effectiveness of the horizontal tail in producing pitching moments by reducing the component of area normal to the horizontal. Finally, during takeoff and landing scenarios, where yaw control and stability are key, the magnitude of tail 


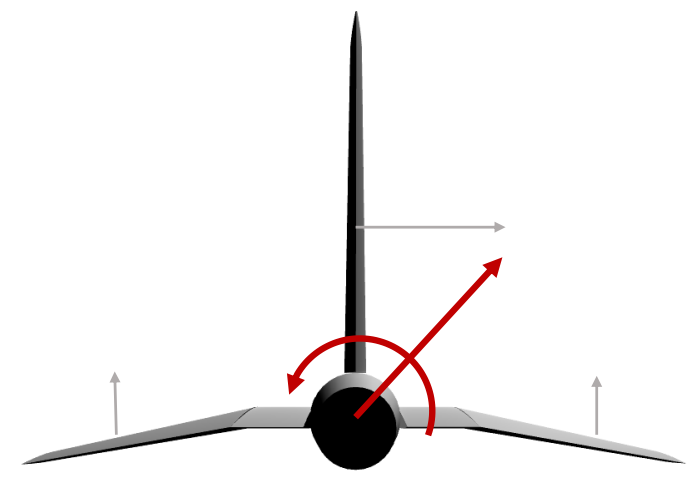

Traditional Empennage

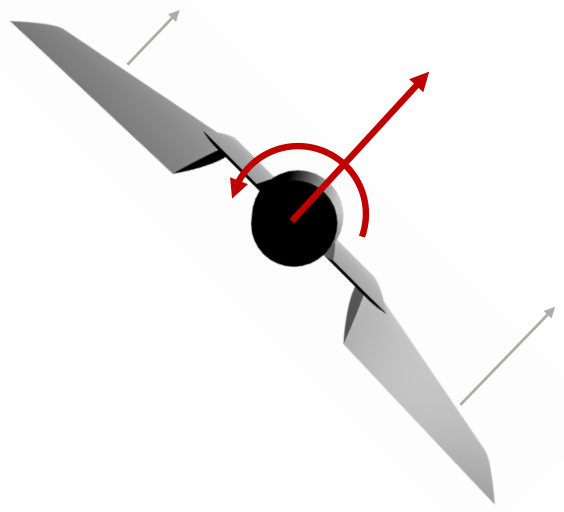

BIRE Design

Fig. 2 The BIRE design can create same net force and moment (red) as a traditional empennage using the additional degree-of-freedom provided by rotation of the empennage.

rotation is limited by the possibility of a tail strike.

This work presents initial efforts to understand these limitations by characterizing the ability of the BIRE to provide both yaw and pitch control at a single flight condition. The control capabilities of the BIRE will be compared to the baseline aircraft by defining the attainable moment set (AMS) at a given equilibrium condition. Defining the attainable moment set of the BIRE design will use a simplified version of the methodology presented by Bolender and Doman [28], which is based upon the work by Durham [29, 30]. The extremal points of the AMS of the aircraft incorporating the BIRE control system (hereafter referred to as the BIRE variant) can be compared to the extremal points of the AMS of the baseline aircraft to provide insight into the control capabilities of the BIRE variant.

In addition, preliminary steps to understanding the capability of the BIRE to provide active pitch and yaw stabilization will be taken by comparing the moment set actuation time (MSAT) of the BIRE variant to the baseline aircraft. The MSAT gives an indication of the amount of time it takes for the control system of an aircraft to reach any moment set in the AMS from an equilibrium position. By determining the MSAT for both the BIRE variant and baseline aircraft at each point in the AMS, the regions in the AMS that will take longer to reach with the BIRE variant can be identified. If the regions where the MSAT is large represent critical areas in a flight envelope, faster actuators will be required for the BIRE design.

This work first describes the geometric and operational characteristics of the baseline aircraft used in this study as well as its BIRE variant. The aerodynamic model used to describe the force and moment coefficients acting on the aircraft is then described as a precursor to presenting trim results for the flight condition being analyzed. Finally, comparisons between the baseline aircraft and its BIRE variant are made considering both the AMS and MSAT to determine potential benefits and drawbacks to implementing the BIRE control system. Note that this work focuses exclusively on an analysis of aerodynamic control. Therefore, no comparison will be made between performance of the baseline aircraft and its BIRE variant in this work, nor will we address the effects of the location of the center of gravity (CG) or weight. Moreover, while the analysis being performed to fit the actuation system into the BIRE is ongoing, it is assumed that the BIRE control system is able to fit the proper actuation devices into the space available in the empennage.

\section{Characteristics of the Baseline Aircraft and its BIRE Variant}

The representative platform to study the BIRE project is a single engine, supersonic, tactical aircraft, similar to the F-16 Fighting Falcon [31]. This platform was chosen partly to decrease the mechanical complexity inherent in applying the BIRE control system to a multi-engine aircraft. In this section, we will provide an outline of the relevant geometric and operational characteristics of the fighter aircraft chosen for this work. Geometric changes made to the aircraft with the addition of the BIRE control system will also be described. Although in this work we will focus on analyzing the aerodynamic control characteristics of the BIRE when integrated into a fighter-type aircraft, a control system similar to 
the BIRE could potentially be applied to nearly any aircraft with a traditional empennage including fighter, transport, passenger, or general aviation aircraft.

\section{A. Geometric Characteristics}

A basic outline of the geometry of the baseline aircraft is included for reference in Fig. 3 with dimensions given in feet [32]. Figure 3 includes the total length and semispan of the aircraft, the spanwise location and length of the mean aerodynamic chord, $c_{\text {ref }}$, and the location of the center of gravity, as measured from the leading-edge of the root chord, as a fraction of the mean aerodynamic chord, $\hat{x}_{\mathrm{cg}_{\text {ref }}} / c_{\text {ref }}$. Geometric characteristics relevant for an aerodynamic analysis of the baseline aircraft lifting surfaces are included in Table 1. Note from Fig. 3 that the chine near the nose of the aircraft, which is used to allow aircraft to sustain lift at high angles of attack, smoothly blends into the main wing and that the fuselage aft of the main wing roughly retains the same width as that of the chine. The section of the fuselage aft of the main wing will factor into the design of the BIRE.
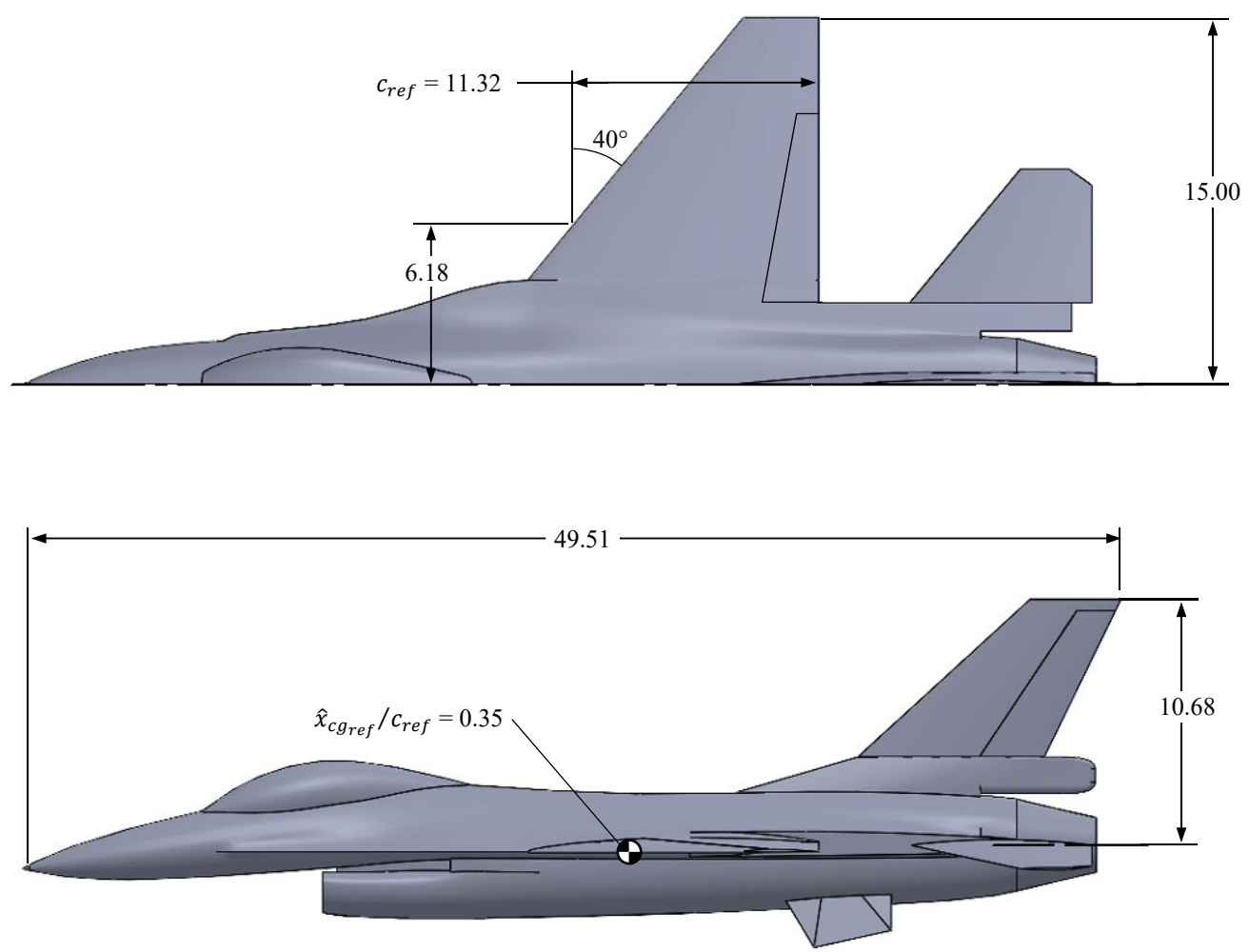

Fig. 3 Geometry and general dimensions of the baseline fighter aircraft. All dimensions in feet.

Both the baseline aircraft and the BIRE have the same main wing and fuselage. Therefore, we will focus here on the differences in the empennage of the two aircraft, which are given visually in Fig. 4 Although the baseline fighter aircraft shown in Fig. 3 includes ventral fins, these have been removed and will not be included in the aerodynamic analysis for the baseline aircraft or its BIRE variant. A detailed drawing for the empennage region of the baseline fighter aircraft at some instantaneous stabilator deflection, $\delta$ (including the effects of both symmetric and antisymmetric deflection), is shown in Fig. 4a. The vertical stabilizer of the baseline aircraft has a planform area of $54.7 \mathrm{ft}^{2}$, based upon a span that runs from the tip of the stabilizer to the upper edge of the fuselage, and a $14.76 \mathrm{ft}^{2}$ rudder with a deflection range of $\delta_{r}= \pm 30^{\circ}$.

Each horizontal stabilator has a $7.89 \mathrm{ft}$ chord at the intersection of the stabilator with the chine, a planform area of $31.9 \mathrm{ft}^{2}$, and a $10^{\circ}$ anhedral angle. Note from Table 1 that the leading-edge sweep of the horizontal tail matches the leading-edge sweep of the main wing, which is typical for supersonic tactical aircraft. Each stabilator rotates about a pivot shaft at the $46 \%$ chord station and is able to deflect symmetrically to a range of $\delta_{e}= \pm 20^{\circ}$. To provide roll control at supersonic speeds, each stabilator has an antisymmetric deflection range of $\delta_{a}= \pm 5.375^{\circ}$ yielding a total saturation deflection range of $\delta_{h}= \pm 25^{\circ}$. 
Table 1 Geometric characteristics of the lifting surfaces on the baseline fighter aircraft.

\begin{tabular}{lccc}
\hline \hline Parameter & Main Wing & Horizontal Tail & Vertical Tail \\
\hline Planform Area, $S,\left[\mathrm{ft}^{2}\right]$ & 300 & 63.7 & 54.7 \\
Span, $b,[\mathrm{ft}]$ & 30 & 11.60 & 8.41 \\
Aspect Ratio, $R_{A}$ & 3.0 & 2.11 & 1.29 \\
Taper Ratio, $R_{T}$ & 0.2275 & 0.39 & 0.45 \\
Mean Geometric Chord, $\bar{c},[\mathrm{ft}]$ & 10.0 & 5.49 & 6.50 \\
Leading-Edge Sweep, $\Lambda_{L E},[\mathrm{deg}]$ & 40 & 40 & 47.5 \\
Quarter-Chord Sweep, $\Lambda,[\mathrm{deg}]$ & 32 & 32 & 38.6 \\
Dihedral, $\Gamma,[\mathrm{deg}]$ & 0 & -10 & 90 \\
Airfoil & NACA 64A204 & NACA 0005 & NACA 0004 \\
\hline \hline
\end{tabular}

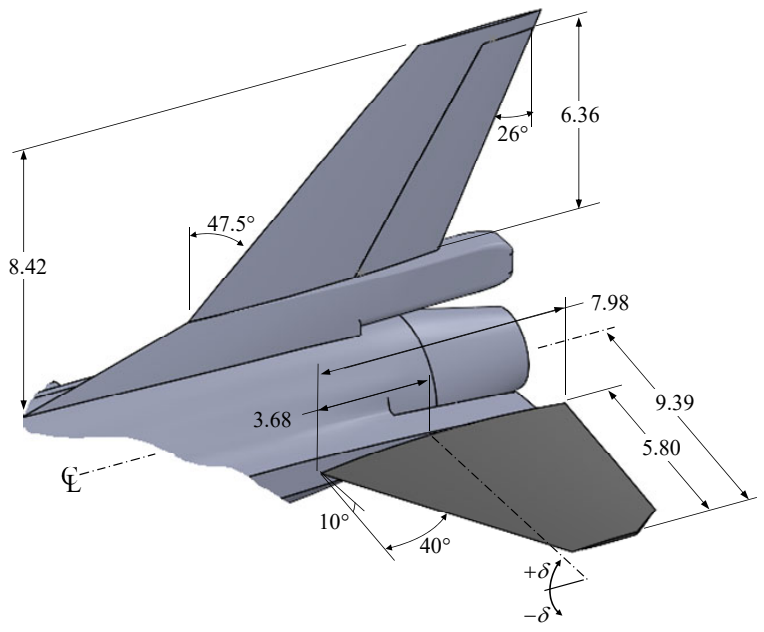

(a) Baseline aircraft

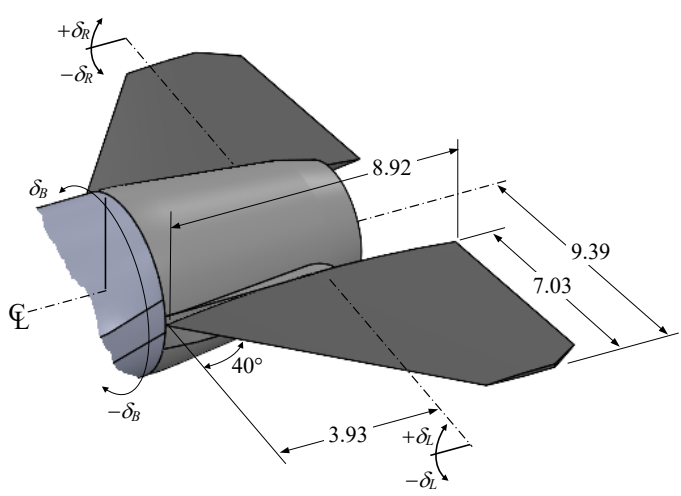

(b) BIRE variant

Fig. 4 Empennage geometry of the baseline tactical aircraft and its BIRE variant.

For the proposed BIRE concept, the vertical tail is removed, and the previously mentioned three degree-of-freedom control system is included: having symmetric (1) and antisymmetric (2) stabilator deflections as well as the solid-body rotation of the empennage about the centerline of the aircraft (3). A detailed drawing of the BIRE empennage can be seen in Fig. $4 \mathrm{~b}$. As each of the stabilators are able to deflect differentially, the instantaneous deflections, $\delta_{L}$ and $\delta_{R}$ may be different, but related antisymmetrically. These instantaneous deflections are shown to be zero in Fig. $4 \mathrm{~b}$ In addition, Fig. $4 \mathrm{~b}$ indicates that the BIRE variant may assume some empennage rotation angle, $\delta_{B}$, with the figure showing a zero deflection angle. The entire empennage of the BIRE design has the ability to rotate about the roll axis with limits of $\delta_{B}= \pm 90^{\circ}$. Additionally, the left and right horizontal stabilators independently rotate to a saturation value of $\delta_{h}= \pm 25^{\circ}$ about the same pivot point as the baseline aircraft with equivalent symmetric and antisymmetric deflection limits.

The planform and fuselage of the BIRE design had to be altered slightly from the baseline model to accommodate the changes in control presented by the BIRE. To allow the empennage to rotate more easily and present a more tractable mechanical system, the fuselage in the BIRE variant tapers to a $5.09 \mathrm{ft}$ diameter circular cross-section located 39.66 $\mathrm{ft}$ from the nose of the aircraft. With the tapering of the fuselage to the engine diameter, the planform area of each stabilator increased from $31.9 \mathrm{ft}^{2}$ to $43.01 \mathrm{ft}^{2}$ to maintain the same wing tip location, thereby increasing the chord at the empennage intersection and the span of the horizontal tail. To retain the same leading-edge sweep as the main wing, the area of the notch on the trailing-edge corner of the horizontal tail was also adjusted. 


\section{B. Operational Characteristics}

The flight conditions that are examined in this work are based upon those outlined in Roetman et al. [24] and Dorsett and Mehl [23], both of which focused on tailless fighter aircraft control systems. Figure 5 shows an estimated flight envelope, based upon a flight envelope for a supersonic aircraft given in Conners and Sims [33], for the baseline aircraft with the operational points of interest identified. The operational points in Fig. 5 are based upon those studied by Roetman et al. [24], since the aircraft that they studied is similar to that used in this work. Note that the labels for the flight conditions indicate the following: " $T$ " for a condition relating to the takeoff or landing of the aircraft, "C" representing a flight condition related to the combat capabilities of the aircraft, and " $\mathrm{S}$ " referring to a supersonic flight condition. In a few cases, the exact flight conditions used by Roetman et al. [24] were altered to reference the flight envelope in Fig. 5] while still being representative of the general flight condition given by Roetman et al. [24].

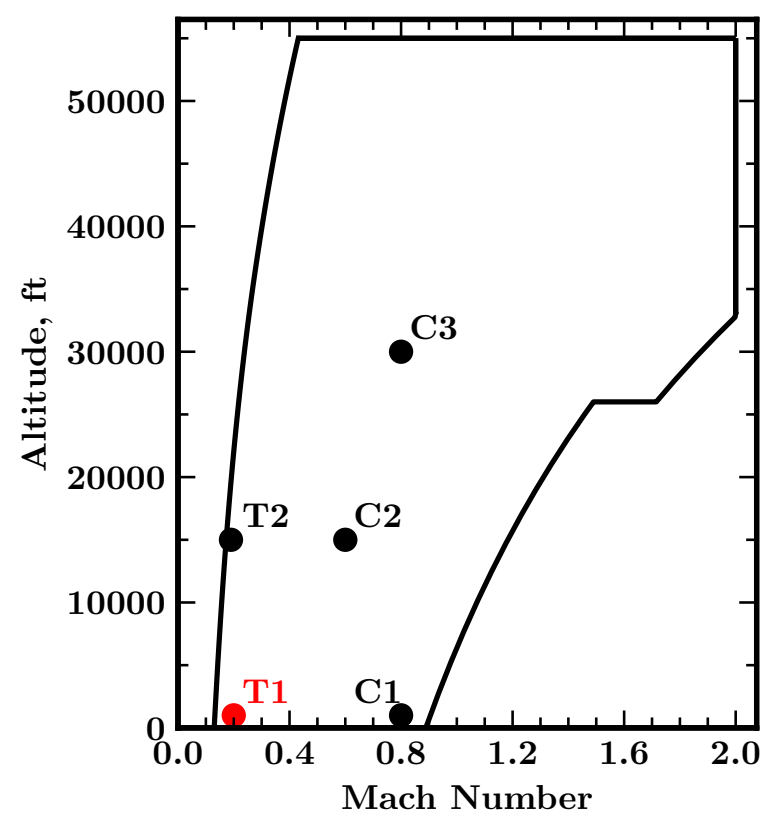

Fig. 5 Estimated flight envelope for the baseline aircraft with operational points of interest identified.

Table 2 Flight conditions of interest. Flight condition T1 is the focus of this work.

\begin{tabular}{ccccc}
\hline \hline Condition Label & Description & Altitude [ft] & Velocity [ft/s] & Mach Number \\
\hline T1 & Take-off and Approach & $\mathbf{1 , 0 0 0}$ & $\mathbf{2 2 2}$ & $\mathbf{0 . 2}$ \\
T2 & Power-On Departure Stall & 15,000 & 201 & 0.19 \\
C1 & Air Combat Maneuver Condition & 15,000 & 634 & 0.6 \\
C2 & Penetration Speed & 1,000 & 1,001 & 0.8 \\
C3 & Maximum Sustained Load Factor & 30,000 & 895 & 0.8 \\
S & Supersonic Condition & 35,000 & 1,946 & 2.0 \\
\hline \hline
\end{tabular}

Each of the operational points identified in Fig. 5 and Table 2 represent relevant points at which to analyze the aerodynamic control capabilities of the baseline aircraft and its BIRE variant. However, this initial study will focus solely on the take-off and approach (T1) flight condition and present preliminary results that will be expanded upon in future work. Flight condition T1 represents primarily a cross-wind landing scenario, which is a critical operational condition for assessing adequate yaw control [20]. Therefore, it is included in this preliminary work as it addresses concerns with coupled pitch and yaw control as well as tail strike. 


\section{Aerodynamic Model and Aircraft Trim}

Determining the AMS and MSAT for the baseline aircraft and BIRE variants requires an estimate of the aerodynamic forces and moments acting on the aircraft in a given flight condition as well as the ability to trim the aircraft in that condition. To provide an estimate of the aerodynamic forces and moments, a low-fidelity aerodynamic model was used to generate an aerodynamic database. A trim condition was then determined by using a linear interpolation of the aerodynamic database within a gradient-based minimization routine. This section gives information on the aerodynamic model and the aerodynamic database, including the limits of the aerodynamic database. The trim condition for steady level flight in flight condition $\mathrm{T} 1$ is also given. The trim solutions for the remaining flight conditions described in Section III.B will be given in future work.

\section{A. Estimation of Aerodynamic Forces and Moments}

The BIRE is an initial design concept that is largely unstudied. Therefore, the aerodynamic model used in this study should be able to perform a broad and rapid design-space exploration with relatively low computational effort. It was determined that MachUpX ${ }^{*}$ an open-source, numerical lifting-line algorithm that can accomodate swept wings would be used [34, 35]. MachUpX has been used for design-space exploration in several studies and is able to produce results rapidly and in good agreement with many higher-fidelity tools including CFD [35, 36].

Figures $6 \mathrm{a}$ and $6 \mathrm{~b}$ show the representations of the baseline aircraft and its BIRE variant respectively as modeled in MachUpX. Note that the lifting surfaces are each extended to the centerline of the aircraft to allow for a continuous distribution of lift and also produce an estimation of fuselage effects. The BIRE variant also includes small vertical lifting surfaces on the empennage to simulate lateral fuselage effects. Although the ailerons are included in the model for the baseline aircraft, they are not used when constructing the aerodynamic database so as to isolate the aerodynamic control provided by the empennage alone.

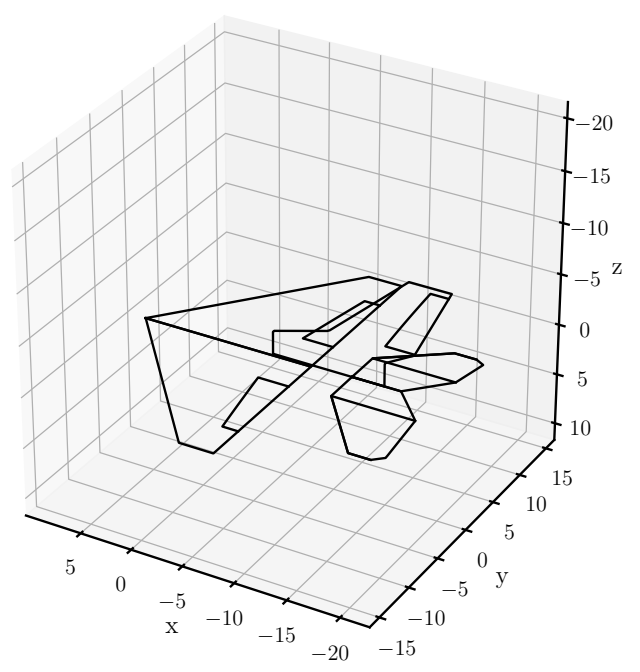

(a) Baseline aircraft

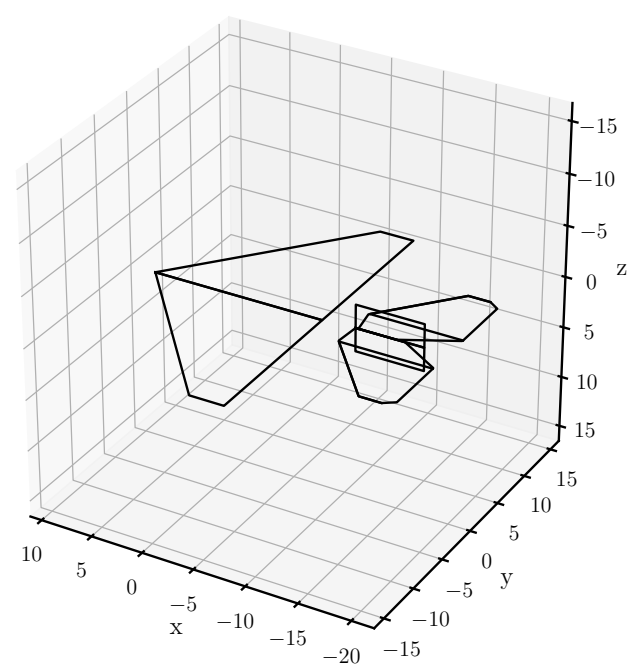

(b) BIRE variant

Fig. 6 MachUpX representation of the baseline aircraft and its BIRE variant.

It should be noted that using numerical lifting-line for geometries such as that chosen in this work can often lead to significant errors in the predicted aerodynamic forces and moments. This is due to both high sweep and low aspect ratios, which produce substantial spanwise flow characteristics that numerical lifting-line does not model. However, in the case of steady level flight, where many of the control surface deflections, the sideslip angle, and the rotation rates are zero, the results produced by MachUpX agree reasonably well with those reported in NASA wind tunnel tests, for example. The wind tunnel data presented by Nguyen et al. [32] for the lift coefficient as a function of angle of attack alone is plotted compared to data from MachUpX in Fig. 7 The lift slope predicted by MachUpX and the data from NASA differ by only $5 \%$. The drag polar generated by MachUpX, shown in Fig. 8. under-predicts the value of the drag as a function of lift coefficient given by the wind tunnel data. The main reason for this difference is likely due to the fact

\footnotetext{
*https://github.com/usuaero/MachUpX
} 
that the numerical lifting-line algorithm does not capture leading-edge vortex shedding, which is common for highly swept wings. This leading-edge vortex shedding can substantially increase the drag. However, this lack of ability in the aerodynamic model is not detrimental to the results of this paper, which focuses on the attainable moments sets. Rather, this low prediction of drag will mainly affect only the thrust required for trim in any condition. Similarly, the change in lift coefficient with stabilator deflection as measured by MachUpX is approximately $40 \%$ greater than that calculated from the wind tunnel data. This is also likely due to the presence of leading-edge vortices, but only affects the trim condition of the aircraft and will not significantly affect the comparison between the baseline aircraft and the BIRE, which is the topic of this paper.

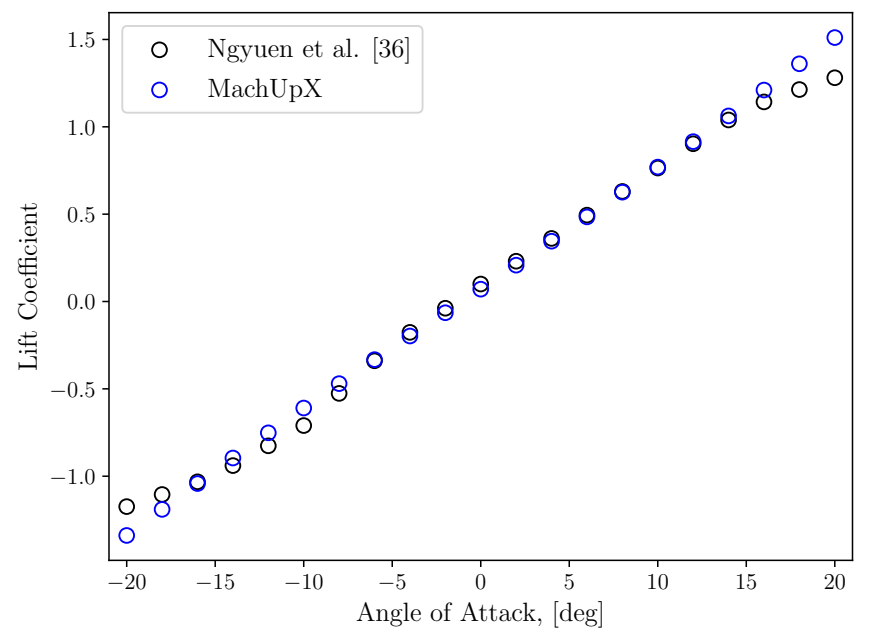

Fig. 7 Comparison in lift coefficient as a function of angle of attack between MachUpX and Nguyen et al. [32].

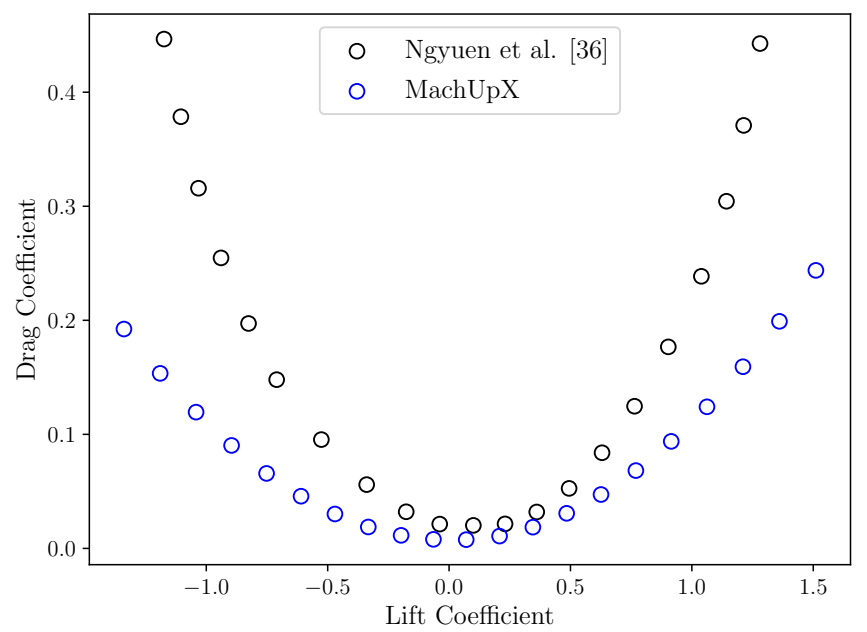

Fig. 8 Drag polar comparison between MachUpX and Nguyen et al. [32].

It should also be noted that there are inconsistencies when the pitching moment is measured as a function of the angle of attack, as shown in Fig. 9. This likely is a result of large sensitivities in the location of the center of gravity for this aircraft. By simply shifting the reference $\mathrm{CG}$ by one inch, which is well within the tolerance to which we can estimate its location, the pitching moment slope predicted by MachUpX is within $3 \%$ of that predicted by the NASA wind tunnel results. The resulting pitching moments from MachUpX after applying the shift in reference CG are highlighted in red in Fig. 9. The change in pitching moment coefficient with stabilator deflection as measured by MachUpX with the same shift in reference CG is approximately $40 \%$ greater in magnitude than that calculated from the 
wind tunnel data. This aligns with the results from the change in lift coefficient with stabilator deflection and is also likely caused by the presence of leading-edge vortices. Note that this will cause both the baseline and BIRE variant results in pitching moment to be scaled by about $40 \%$, but should not affect the comparison between the two aircraft. Thus, while a numerical lifting-line method such as MachUpX is not able to accurately predict the aerodynamic force and moment coefficients in all flight conditions, the results in this case are representative and can be used as part of an initial study on the baseline aircraft and its BIRE variant.

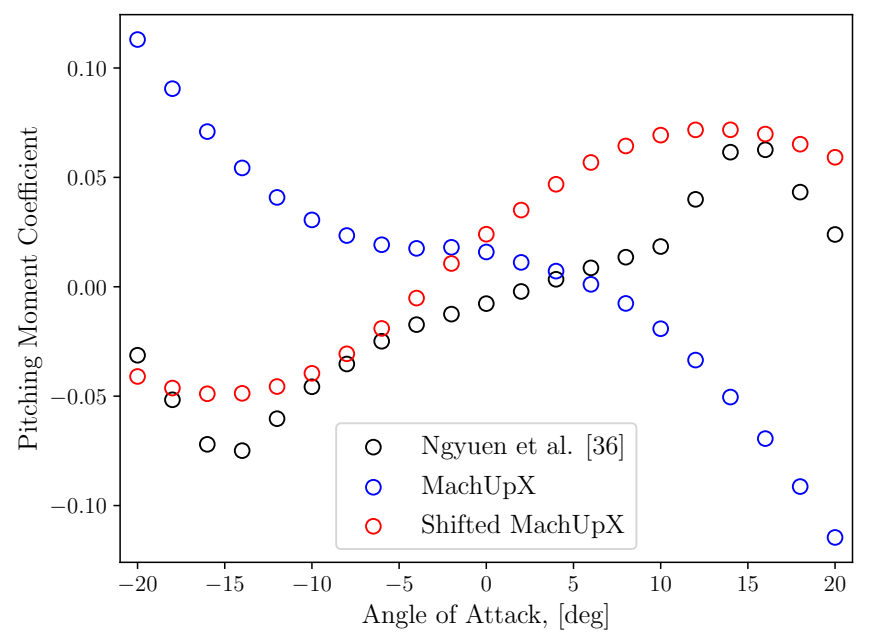

Fig. 9 Comparison in pitching moment coefficient as a function of angle of attack between MachUpX and Nguyen et al. [32].

\section{B. Aerodynamic Database and General Trim Algorithm}

The aerodynamic forces and moments acting on an aircraft can be calculated as a function of the aerodynamic angles, the control surface deflections, and the body-fixed rotation rates. Using MachUpX, a 390,625 point aerodynamic database was generated for both the baseline fighter aircraft and the BIRE variant by defining the aerodynamic forces and moments for every combination of 5 points in each of the 8 parameter dimensions mentioned above $\left(5^{8}=390,625\right)$. The limits of each of the 8 parameters in the database are shown in Table 3 . The stabilator deflection, $\delta_{e}$, and the differential tail deflection, $\delta_{d}$, are equivalently defined between the baseline and BIRE variants. Where the two models differ is in the final control surface deflection: where $\delta_{r}$ is used to represent a traditional rudder deflection of the baseline aircraft and the BIRE variant defines $\delta_{B}$ as the solid body empennage rotation. Also included in Table 3 are the actuation rates for each control system based on values given by Stevens and Lewis [37]. Each degree of freedom contained 5 equally-spaced points between the given limits. Since the BIRE rotation angle is not a traditional flap deflection, the aerodynamic database for the BIRE variant took longer to generate. Using parallel processing across 24 Intel Xeon cores at the University of Utah Center for High Performance Computing (CHPC) the generation of a database for flight condition T1 using MachUpX took 28 minutes for the baseline aircraft and 40 minutes for its BIRE variant.

In this study, we will focus on the steady level flight trim condition. Steady level flight is a special case of the steady coordinated turn where the bank angle, $\phi$, as well as the rotational velocities, $p, q$, and $r$, are all zero. Under these conditions, the longitudinal aircraft equations of motion become

$$
\begin{aligned}
& \frac{1}{2} \rho V^{2} S_{w} C_{x}\left(\alpha, \delta_{e}\right)-W \sin \theta=0 \\
& \frac{1}{2} \rho V^{2} S_{w} C_{z}\left(\alpha, \delta_{e}\right)+W \cos \theta=0
\end{aligned}
$$

and

$$
\frac{1}{2} \rho V^{2} S_{w} \bar{c}_{w} C_{m}\left(\alpha, \delta_{e}\right)=0
$$

\footnotetext{
†https://www.chpc.utah.edu/
} 
Table 3 Limits for each degree of freedom in the aerodynamic database for the baseline fighter aircraft and its BIRE variant.

\begin{tabular}{cccc}
\hline \hline Parameter Name & Description & Database Limits & Actuation Rate (deg/s) \\
\hline$\alpha$ & Angle of Attack & $\pm 15^{\circ}$ & - \\
$\beta$ & Sideslip Angle & $\pm 15^{\circ}$ & - \\
$\delta_{e}$ & Stabilator Deflection Angle & $\pm 25^{\circ}$ & 60 \\
$\delta_{d}$ & Differential Tail Deflection Angle & $\pm 5.375^{\circ}$ & 80 \\
$\delta_{r}$ & Baseline Aircraft Rudder Deflection & $\pm 30^{\circ}$ & 120 \\
$\delta_{B}$ & BIRE Rotation Angle & $\pm 90^{\circ}$ & 120 \\
$p$ & Body-fixed Roll Rate & $\pm 70 \mathrm{deg} / \mathrm{s}$ & - \\
$q$ & Body-fixed Pitch Rate & $\pm 70 \mathrm{deg} / \mathrm{s}$ & - \\
$r$ & Body-fixed Yaw Rate & $\pm 20 \mathrm{deg} / \mathrm{s}$ & - \\
\hline
\end{tabular}

Note that, since steady level flight is a purely longitudinal trim condition in a symmetric aircraft, the lateral forces and moments must be entirely zero.

The system given by Eqs. (1)-(3) has two unknowns: the angle of attack, $\alpha$, and the stabilator deflection, $\delta_{e}$, which prescribe the aerodynamic force and moment coefficients. These two unknown parameters can be used in conjunction with Eqs. (2) and (3) to define the trim angle of attack and stabilator deflection. Equation (1) in this trim problem is therefore useful only to determine the amount of thrust required to offset the drag of the aircraft, but we require an additional parameter to be defined. This parameter is defined by separating the force in the $x$-direction into two components: the aerodynamic force produced in the $x$-direction as given in the aerodynamic database, and the force of thrust, which is assumed to be entirely in the $x$-direction. Thus, by substituting the relation

$$
C_{x}=C_{x_{A}}+C_{x_{T}}
$$

into Eq. (1), our new system becomes

$$
\frac{1}{2} \rho V^{2} S_{w}\left(C_{x_{A}}\left(\alpha, \delta_{e}\right)+C_{x_{T}}\right)-W \sin \theta=0
$$

in conjunction with Eqs. (2] and (3). In this work, the Broyden-Fletcher-Goldfarb-Shanno method [38-41] was used to determine the values of $C_{x_{T}}, \alpha$, and $\delta_{e}$ required to satisfy Eqs. (2), (3), and (5).

The trim condition for the baseline aircraft and its BIRE variant in steady level flight at flight condition T1 is shown in Table 4. Note that the increased tail area of the BIRE variant allows trim to be achieved with a smaller stabilator deflection angle, $\delta_{e}$, than the baseline aircraft. The trim angles of attack are nearly identical at this condition because the main wing produces the majority of the lift on each aircraft and is kept constant between the two configurations.

Table 4 Trim condition in steady level flight for flight condition $\mathrm{T} 1$.

\begin{tabular}{lcc}
\hline \hline Trim Parameter & Baseline Aircraft & BIRE Variant \\
\hline$F_{x_{T}},[\mathrm{lbs}]$ & -3625 & -3671 \\
$\alpha,[\mathrm{deg}]$ & 17.6 & 17.9 \\
$\delta_{e},[\mathrm{deg}]$ & -8.3 & -6.3 \\
\hline
\end{tabular}

\section{Comparison of the Attainable Moment Set}

The AMS represents a bounded volume in moment-space (where the dimensions are given by the aerodynamic moments on the aircraft) composed of all possible moment combinations that can be reached from an equilibrium condition using constrained control effector deflections. Using the trim condition at flight condition T1 outlined in the previous section, the AMS of the aircraft about its trim point can be determined. The extremal points of the AMS at a 
given flight condition give an indication of the maximum controlling moments available to an aircraft [23]. Therefore, by comparing the AMS between the baseline aircraft and its BIRE variant, any benefits to aerodynamic control made by the BIRE system can be determined, as well as trade offs between pitching and yawing moments.

An estimate for the AMS of the baseline aircraft and its BIRE variant can be obtained by using the aerodynamic database of each aircraft to estimate the combination of aerodynamic moments over a sweep of all possible control surface deflection combinations. A sampling of the AMS for both the baseline aircraft and its BIRE variant are shown in Figs. 10 and 11 respectively. The deflection limits for each control surface ensure that, when plotted, the AMS exists within a bounded volume.

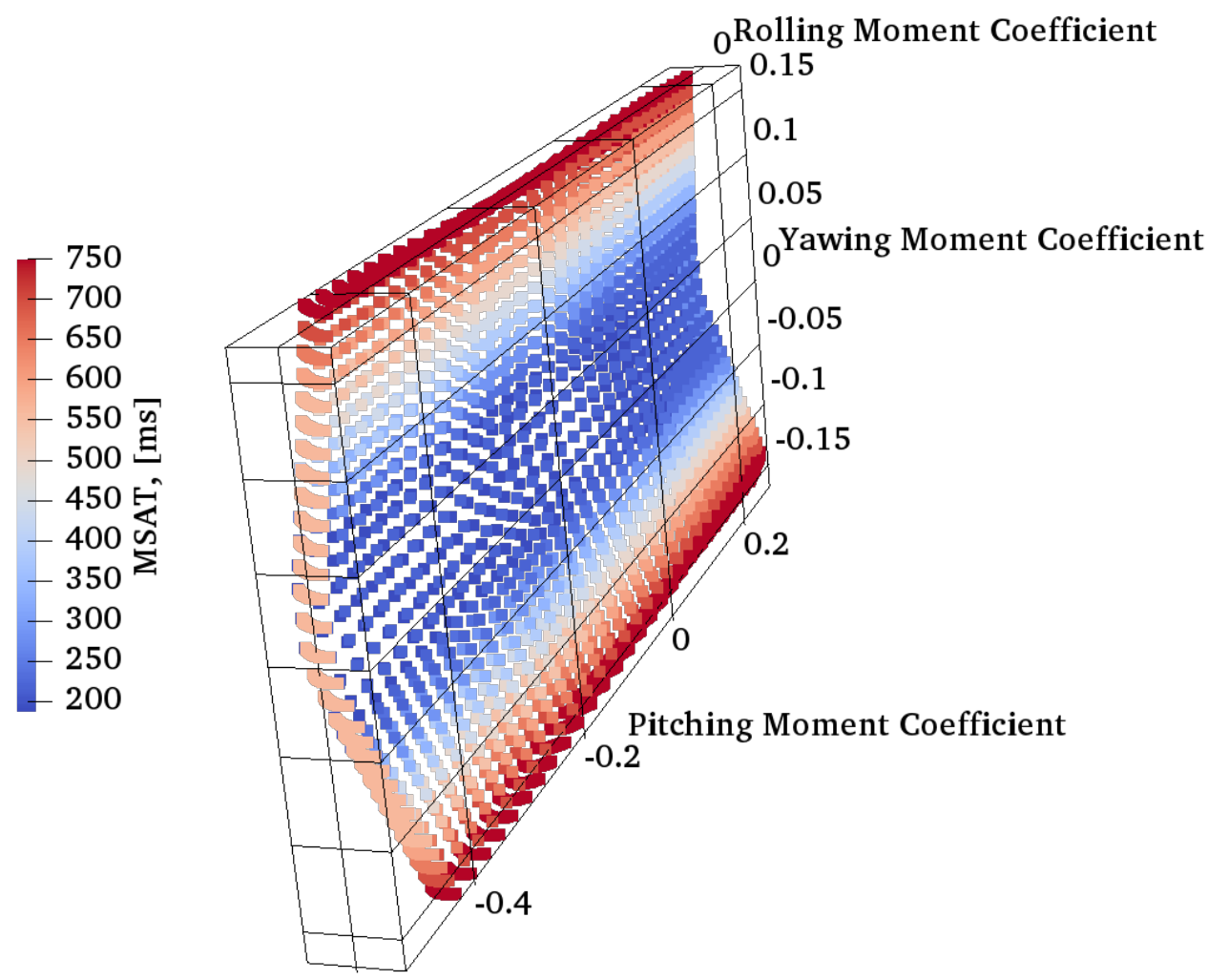

Fig. 10 AMS samples for the baseline aircraft about the steady level flight trim point at flight condition T1.

Assuming that the set of attainable aerodynamic moments in the sampled AMS is convex, the process of identifying the boundary surface can be described mathematically using a convex hull [42]. Since we cannot guarantee that each set of points is convex, and, in fact, the AMS shown in Fig. [10]is not, an alpha shape [43] can be used to identify the boundary and thus the AMS for each aircraft. By adjusting a parameter in the alpha shape, the algorithm can be adjusted to accommodate different levels of concavity in a data set and properly represent the AMS extremal points. An alpha shape represents a more general form of the convex hull that allows for concavity in the set, but is generally only defined for two-dimensional sets. For an AMS, such as those shown in Figs. 10 and 11, a 3-D triangulation method, such as a Delaunay triangulation [44, 45] can be used to identify the extremal surface of the AMS.

To help visualize the AMS of each aircraft, a two-dimensional slice of the three-dimensional space can be examined at a constant value of the moment coefficient in the third dimension. Since these slices are two-dimensional, an alphashape can be defined to form the outer boundary of the AMS. Figs. 12-14 show two-dimensional slices of the three-dimensional space for the baseline aircraft and its BIRE variant. In this case, the slices are taken in the plane where the aerodynamic moment in the third dimension is zero. For example, Fig. 12 is a slice showing the AMS of the pitch and yaw dimensions with zero rolling moment.

From Figs. 12 and 14, we note that, as intuition suggests, the BIRE variant is able to increase the attainable aerodynamic moments about the yaw axis by up to $170 \%$ from the baseline. When rotated into the vertical position, the stabilators function as two all-moving vertical stabilizers, more than doubling the pure yawing moment available. It is important to note from Fig. 12 that there is no substantial reduction in available pitching moment from rotating the tail. 


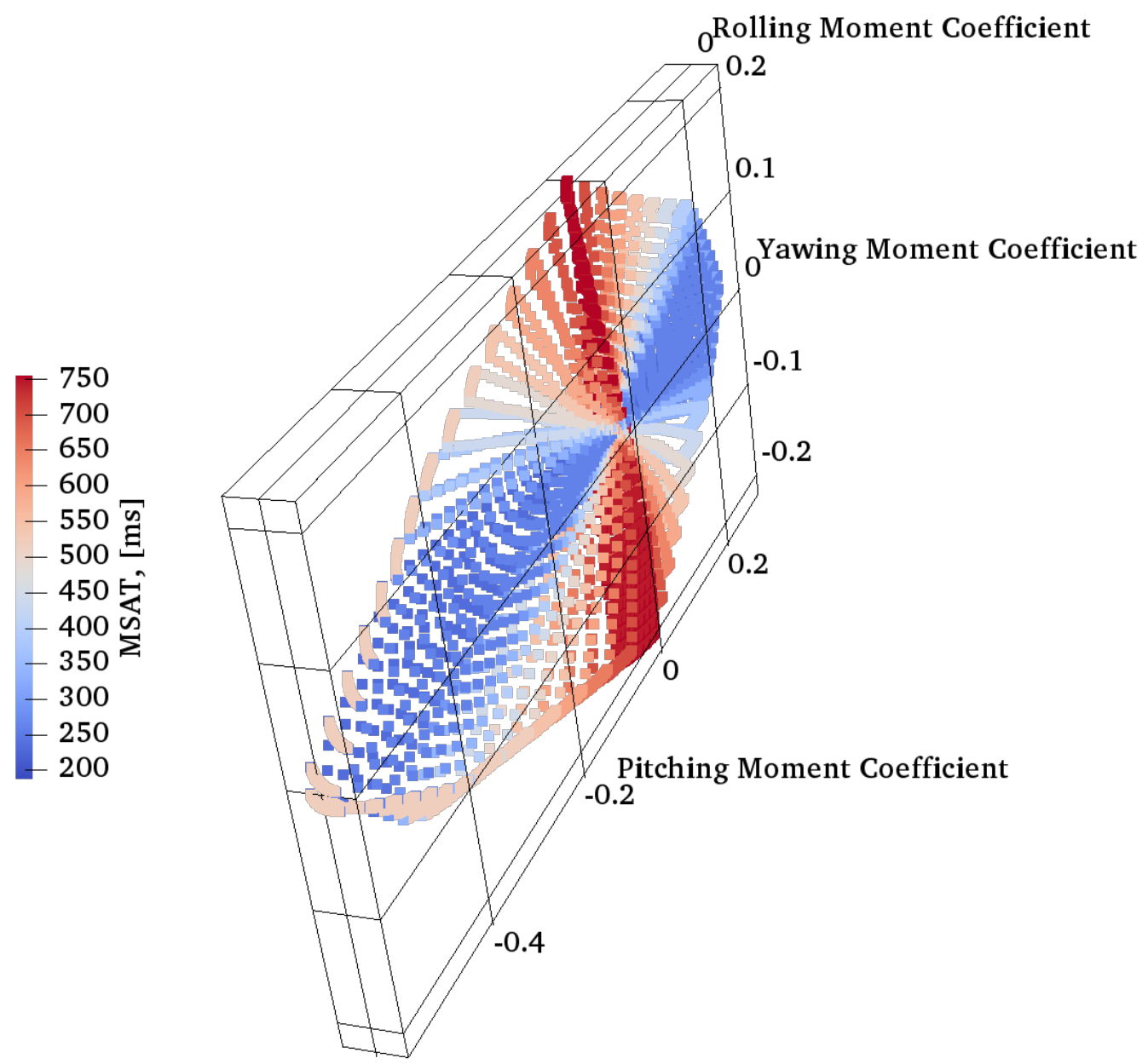

Fig. 11 AMS samples for the BIRE variant about the steady level flight trim point at flight condition T1.

In fact, the available pitching moment is increased by about $10 \%$ in some locations. From these slices of the AMS volume, we can therefore rule out any issues regarding the coupling between pitch and yaw in this flight condition.

With zero yawing moment, which would eliminate the need to rotate the tail, the BIRE variant has $10 \%$ more available pitching moment and $70 \%$ more available rolling moment, as shown in Fig. 13. This is due to the slight increase in surface area available in the BIRE variant when compared to the baseline aircraft, allowing for a higher overall moment to be produced by deflecting the stabilators. In addition to the increase in area available on the horizontal tail, when differential tail deflection is used in the baseline aircraft to generate a rolling moment a pressure differential is created on the vertical tail, which generates a rolling moment opposing the desired direction of roll [46]. With the vertical tail removed, this counteracting rolling moment is not generated, leading to an increase in the attainable rolling moment available to the BIRE variant.

The increase in available yawing and pitching moments come at the expense of about $40 \%$ less available rolling moment when constrained to zero pitching moment, as shown in Fig. 14. This result can be understood by recognizing that solid body rotations of the tail section will not create an asymmetrical side force offset from the roll axis, as was the case with the rudder in the baseline aircraft. In other words, the sideforce generated by the rudder in the baseline configuration acts to produce an additional rolling moment that is absent in the BIRE variant. Pilots rarely use the rudder to generate a rolling moment, however, and therefore this slight reduction in available rolling moment provided by the tail is likely inconsequential.

One other observation from Fig. 14 is the reduction in the amount of negative correlation between yawing and rolling moment shown in the AMS of the BIRE variant. The negative correlation in the baseline aircraft is analogous to the adverse yaw experienced when producing a rolling moment; however, in the BIRE variant, this negative correlation is greatly reduced. It remains to be seen whether the reduction in roll control provided by the tail negatively impacts the 


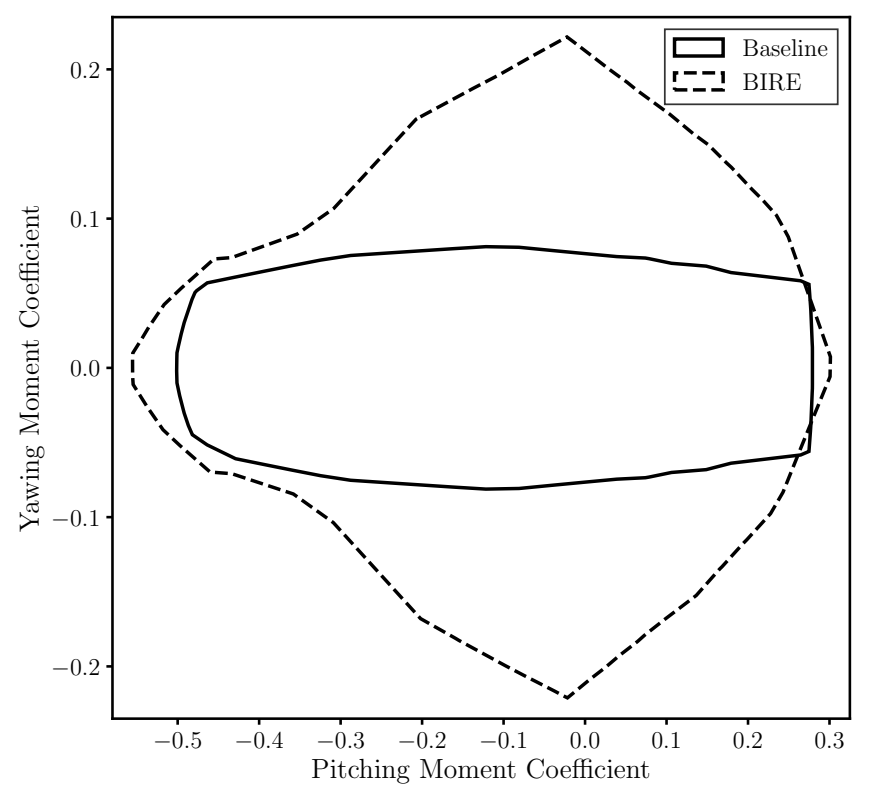

Fig. 12 The yaw and pitch AMS for the baseline aircraft and BIRE variant at flight condition T1 and zero rolling moment.

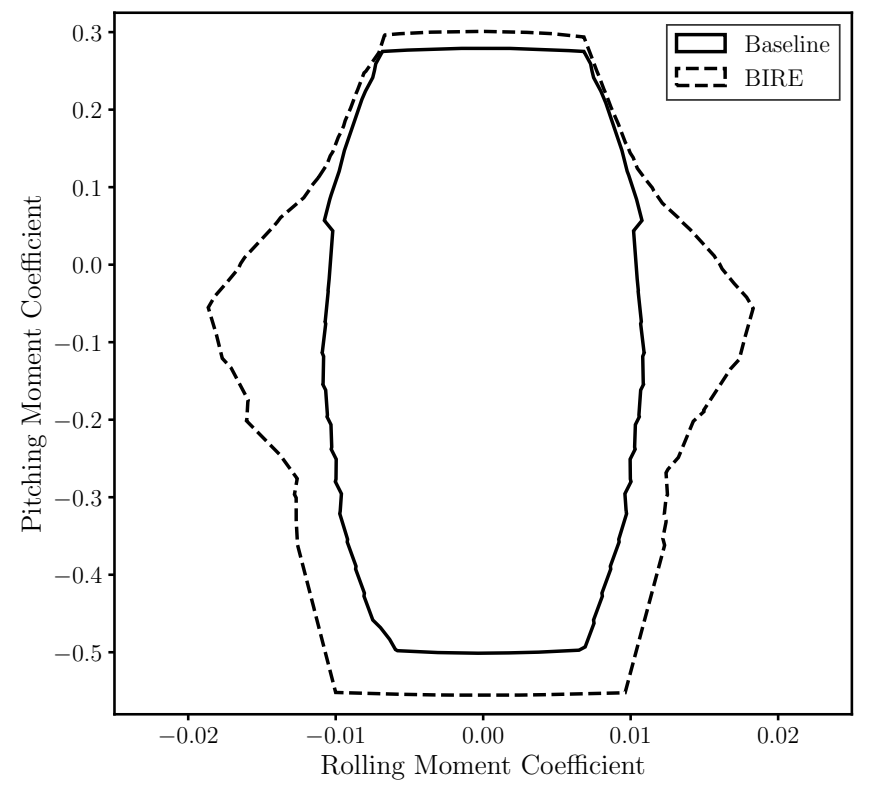

Fig. 13 The roll and pitch AMS for the baseline and BIRE aircraft configurations at flight condition T1 and zero yawing moment.

aircraft in other flight conditions, since the mitigation in the adverse yaw effect may prove to be more beneficial than the slight reduction in attainable rolling moment provided by the tail. This is especially relevant considering that the differential deflections of the horizontal stabilizers are not the primary means of roll control for the aircraft, with the ailerons providing the majority of roll control in subsonic flight regimes. 


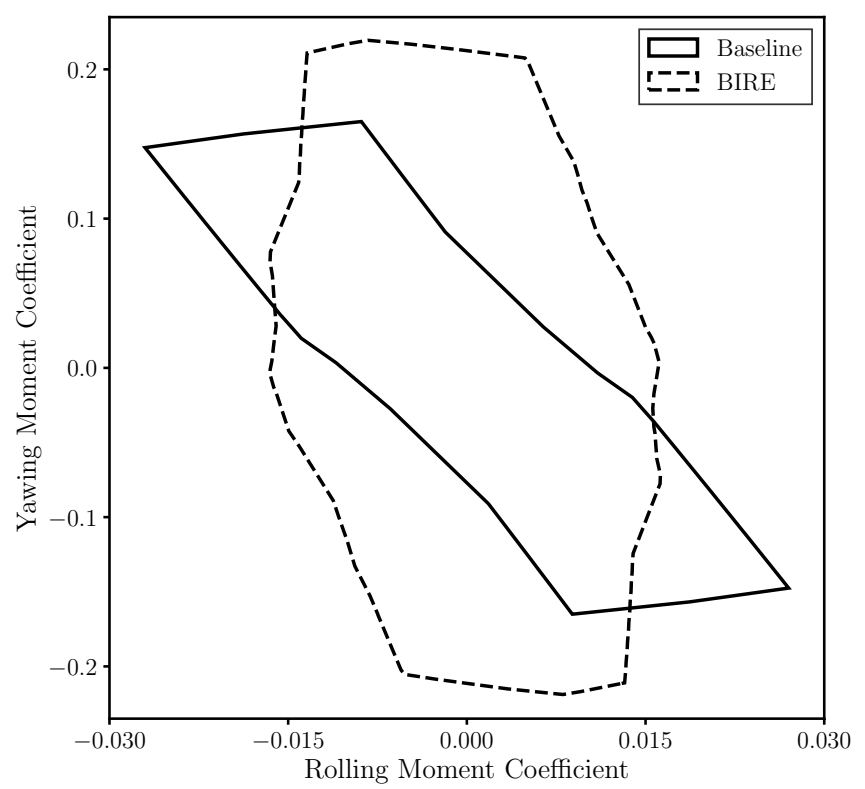

Fig. 14 The roll and yaw AMS for the baseline and BIRE aircraft configurations at flight condition T1 and zero pitching moment.

\section{Comparison of Moment Set Actuation Time}

In the previous section we showed that the BIRE variant is able to produce greater yawing moments than the baseline design without sacrificing pitch control, which was a concern with the design. The other potential issue that can be addressed with this analysis is whether a substantial increase in actuation rate is required for any of the control surfaces in the BIRE to match the MSAT levels of the baseline aircraft. Understanding the difference in actuation time between the two aircraft will indicate the mechanical feasibility of the design.

The time that it takes the aircraft to actuate from its trim position to any point in the AMS domain was defined earlier as the moment set actuation time (MSAT) or just actuation time, $t_{a}$. The actuation rates for the control surfaces in the baseline and the BIRE variant were given in Table 3 . Using these actuation rates, an estimate of the actuation time for each aircraft at a given control moment combination can be made. The MSAT for the baseline aircraft at any given point in the AMS domain is calculated as

$$
t_{a_{\text {baseline }}}=\max \left\{\begin{array}{l}
\left|\delta_{e}-\delta_{e_{\text {trim }}}\right| / \lambda_{e} \\
\left|\delta_{a}-\delta_{a_{\text {trim }}}\right| / \lambda_{a} \\
\left|\delta_{r}-\delta_{r_{\text {trim }}}\right| / \lambda_{r}
\end{array}\right\}
$$

where $\lambda_{e}, \lambda_{a}$, and $\lambda_{r}$ are the actuation rates of the stabilator actuator, differential tail actuator, and rudder actuator respectively. The MSAT for the BIRE variant is defined almost identically as

$$
t_{a_{\mathrm{BIRE}}}=\max \left\{\begin{array}{l}
\left|\delta_{e}-\delta_{e_{\text {trim }}}\right| / \lambda_{e} \\
\left|\delta_{a}-\delta_{a_{\text {trim }}}\right| / \lambda_{a} \\
\left|\delta_{B}-\delta_{B_{\text {trim }}}\right| / \lambda_{B}
\end{array}\right\}
$$

where $\lambda_{B}$ is the actuation rate of the BIRE rotation actuator. Note from Eqs. (6) and (7) that the MSAT is defined as the slowest actuation time to reach a moment set from the trim position among each of the control effectors. Therefore, it is a function of both the amount of deflection and the actuation rates of each control surface.

Figure 15 shows the same two-dimensional slice of the AMS depicted in Fig. 12 with contours of constant MSAT in milliseconds. In this figure and those that follow, the dashed contours indicate the MSAT of the BIRE variant and the solid contours show the MSAT for the baseline aircraft. In Fig. 15 we can see that, at zero rolling moment and low yawing moments, the BIRE variant can more quickly produce pitching moments than the baseline aircraft. This can be 
explained again by the additional surface area available to the horizontal tail of the BIRE by virtue of removing the chine, which increases the stabilator effectiveness. Intuitively, this indicates that the BIRE variant would be able to reach any purely longitudinal flight condition from steady level flight more quickly than the baseline aircraft. However, one potential issue with the BIRE system is that any moment set near pure yawing motion is actuated significantly slower than in the baseline aircraft. To produce a pure yawing moment, the tail of the BIRE variant is required to rotate into a vertical position - a much larger deflection than any of the other control effectors-while the baseline aircraft need only deflect the rudder. However, the need to produce a pure yawing moment and zero pitching or rolling moment is likely extremely rare. In most cases, a yawing moment is needed in addition to at least a pitching moment from the tail in order to produce a desired maneuver. Additionally, it is important to keep in mind that the time shown on the plots is the time required to reach that moment from the steady-level-flight trim condition. If a pure yawing moment is needed, it will likely come during a maneuver, and therefore be obtained somewhat gradually by traversing this three-dimensional moment domain. These types of effects must be considered using a dynamic analysis.

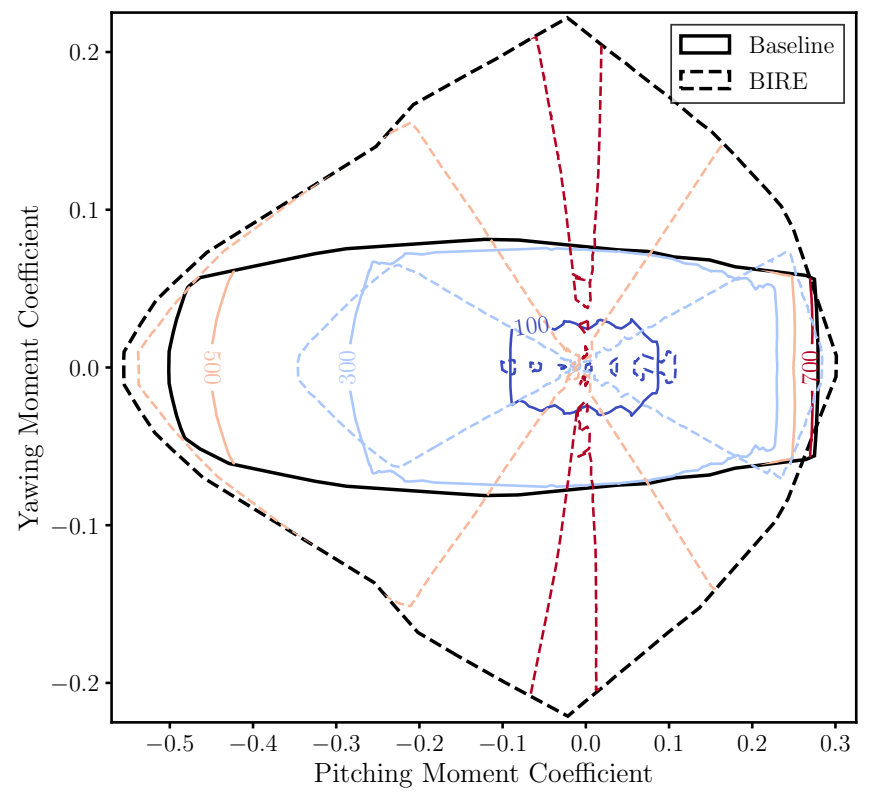

Fig. 15 MSAT contours for yawing and pitching moments at zero rolling moment for the baseline fighter aircraft and its BIRE variant.

A more direct comparison between the baseline aircraft and its BIRE variant can be obtained by finding the difference between the actuation time of the BIRE variant and the baseline aircraft. Contours showing the difference in MSAT between the two aircraft in milliseconds can be seen in Fig. 16 The difference in MSAT between the baseline and the BIRE is defined as

$$
\Delta t_{A}=t_{a_{\text {baseline }}}-t_{a_{\text {BIRE }}}
$$

and thus a positive contour indicates that the BIRE reaches the given control moments faster than the baseline aircraft and vice versa. From Fig. 16, we see the region of small pitching moments where yaw control is up to $600 \mathrm{~ms}$ slower with the BIRE than with the baseline. We can also see that the BIRE produces large pitching moments about $400 \mathrm{~ms}$ faster than the baseline aircraft.

It is important to point out that $600 \mathrm{~ms}$ may represent an insignificant difference in terms of pilot control time for pure yawing motion. However, this difference will be much more consequential with the introduction of a stability augmentation system, which are commonly used on fighter aircraft. Many fighter aircraft use the rudder as an active dampening device to improve dynamic stability, and slow actuation times in the BIRE could negatively impact its ability to provide such active damping. The potential impact of the actuation rates on the stability augmentation system must be addressed in future work, though it is unlikely that an active damping system will require the same magnitude of yawing moments as those identified as potential issues in Fig. 16.

Figure 17 highlights again that the BIRE variant is able to produce large pitching moments approximately $400 \mathrm{~ms}$ faster than the baseline aircraft. The noise in the data at low pitching and rolling moments is likely due to the constraint 


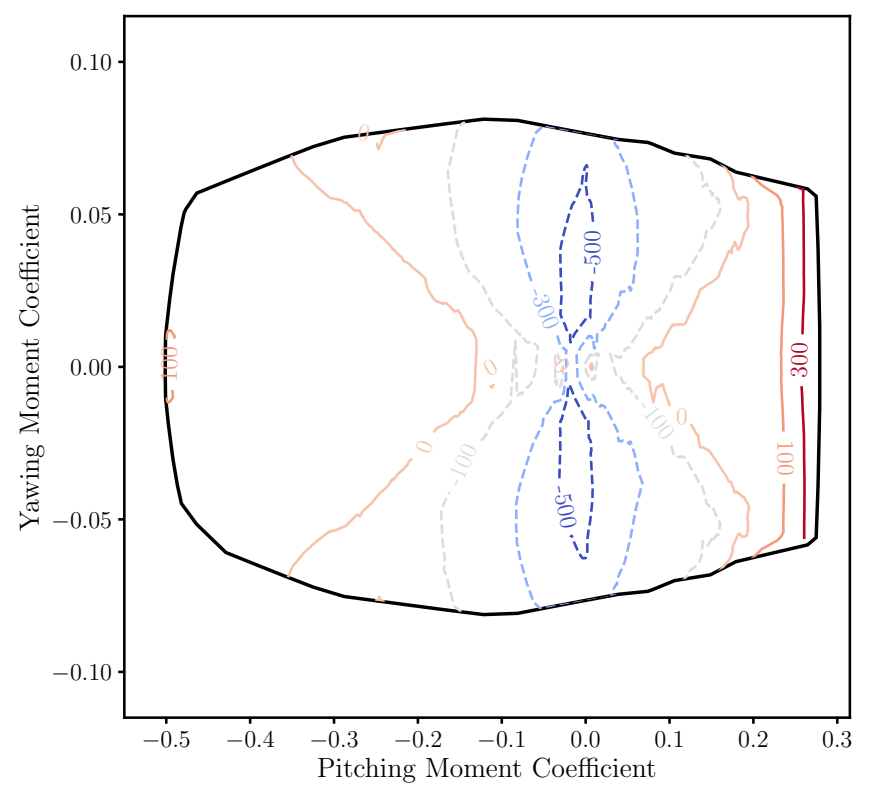

Fig. 16 Difference in actuation time between the baseline aircraft and BIRE variant for yawing and pitching moment sets at zero rolling moment.

on the yawing moment, as these contours are well-defined at larger pitching moments. It is unclear whether this region of high actuation time and actuation time gradient is accurate, though this could possibly be a region where strong coupling between the longitudinal and lateral moments forces the BIRE to rotate through large angles to produce the requisite moments. Such a control configuration would likely require similar time scales as the region of nearly-pure yawing moment in Fig. 15, which we see in Fig. 17] Figure 18 shows the MSAT difference contours for this slice of the AMS. Again, the noisiness of the data leaves little room for a definitive conclusion, as the constraints placed on the BIRE in this slice may not be representative for normal flight maneuvers.

Finally, Fig. 19 gives the MSAT contours for roll-yaw moment sets at zero pitching moment. These moment sets are subject to the same issues involving coupling that were described when discussing the pitch-roll moment sets at zero yawing moment. That is, the coupled nature of the aerodynamic moments in the BIRE variant likely require large deflections to meet the constraints placed upon them in this slice of the moment space. This translates to large MSATs across the moment set combinations seen in Fig. 19 This is shown more explicitly in the actuation time difference contours given in Fig. 20, where the entirety of this slice of the moment space actuates up to $500 \mathrm{~ms}$ slower than the baseline aircraft. While this coupling can be considered a weakness of the BIRE design at flight condition T1, the differential tail is not likely the primary method for producing rolling moments, as was discussed previously. The results from these figures again require that an analysis on a stability augmentation system be performed, as this is where these implications can be understood.

From the results shown above, it seems likely that the BIRE control system could provide the necessary control power and actuation times for the aircraft at flight condition T1. The BIRE variant has available yawing moments up to $170 \%$ greater than the baseline aircraft, although the actuation times are up to $600 \mathrm{~ms}$ slower in some unique conditions. On the other hand, the pitch actuation times are up to $400 \mathrm{~ms}$ faster with the BIRE variant when compared to the baseline aircraft, which is likely a result of the increased stabilator surface area. Finally, although the production of rolling moments is largely handled by the ailerons of the main wing, the BIRE produces less rolling moment at high yawing moments than the baseline aircraft and actuates up to $500 \mathrm{~ms}$ slower in some conditions. The time differences shown in Figs. 16-20 could be much less significant than they appear when considering pilot control time, though they certainly will be important when designing a stability augmentation system. 


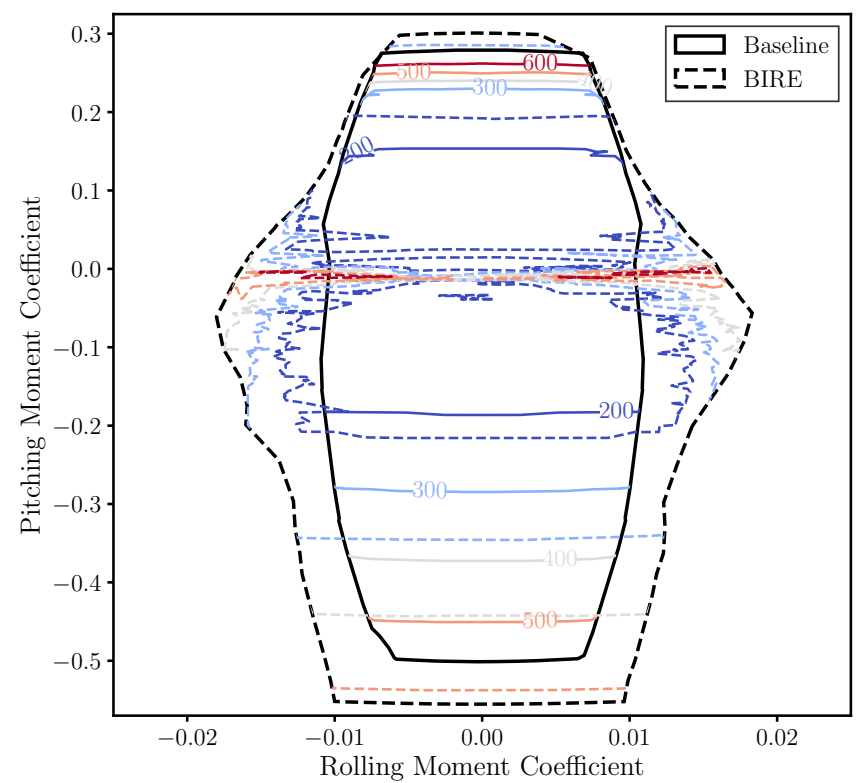

Fig. 17 MSAT contours for rolling and pitching moments at zero yawing moment for the baseline fighter aircraft and its BIRE variant.

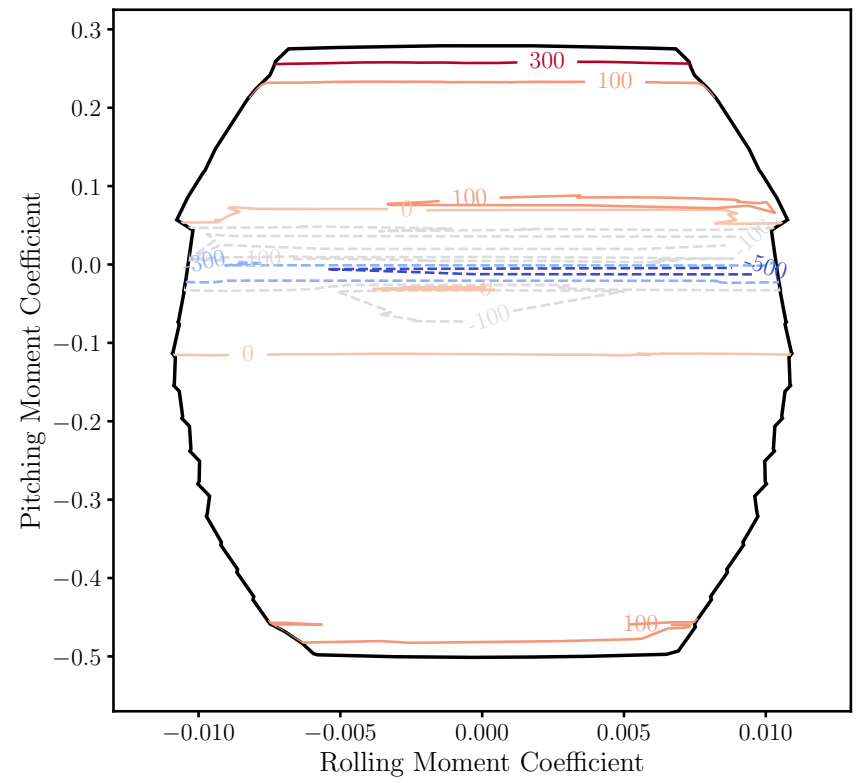

Fig. 18 Difference in actuation time between the baseline aircraft and BIRE variant for rolling and pitching moment sets at zero yawing moment.

\section{Conclusion}

A bio-inspired aircraft control system was introduced in this work for a fighter aircraft based on the F-16 Fighting Falcon. This novel control mechanism, the Bio-Inspired Rotating Empennage (BIRE), allows the entire empennage to undergo solid-body rotations to produce lateral control and stability. Since the BIRE allows the aircraft to produce lateral control and stability through rotation of the horizontal tail, the vertical tail of the fighter aircraft can be removed, providing potential benefits to weight and drag reduction. 


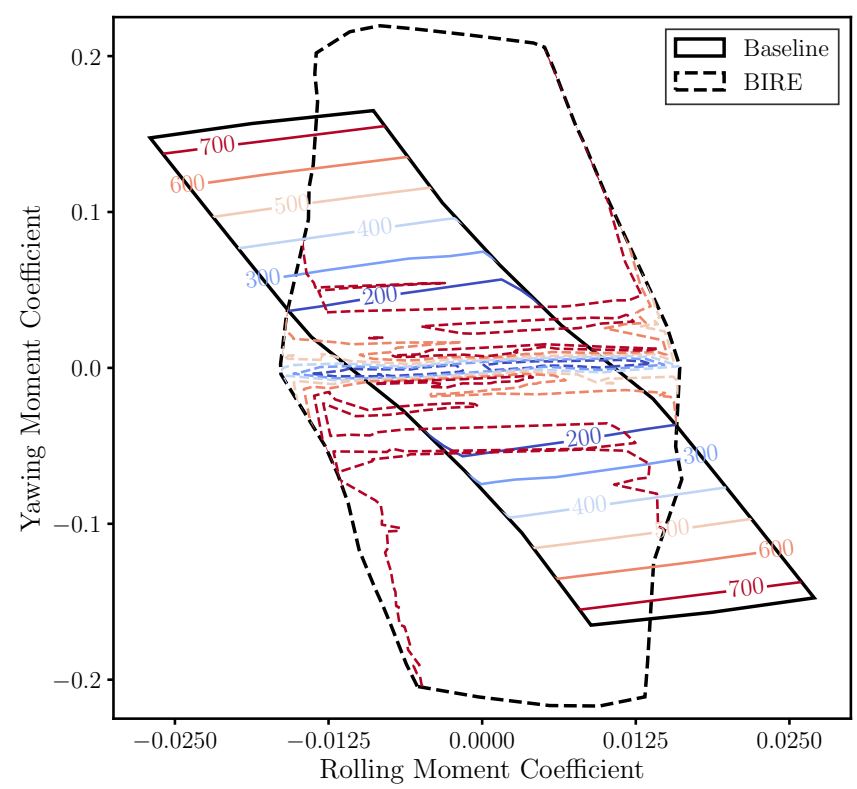

Fig. 19 MSAT contours for rolling and yawing moments at zero pitching moment for the baseline fighter aircraft and its BIRE variant.

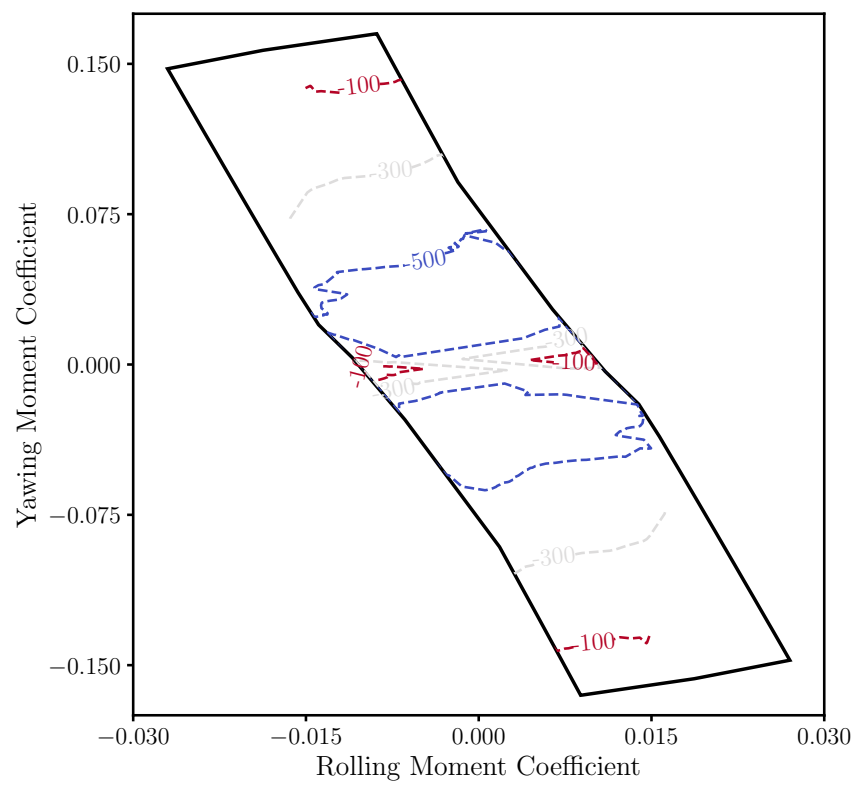

Fig. 20 Difference in actuation time between the baseline aircraft and BIRE variant for rolling and yawing moment sets at zero pitching moment.

An aerodynamic database was constructed using MachUpX, an open-source numerical lifting-line solver, for both the baseline aircraft and its BIRE variant. The database was used to trim each aircraft in steady-level flight at takeoff and approach speeds. Once trimmed, the attainable moment set (AMS) for each aircraft was determined by identifying a sample of the aerodynamic moment sets that each aircraft was capable of achieving from its trimmed condition. This information was then used alongside the approximate actuation rates of each control effector to determine the time required to actuate from the trim point to another point in the AMS domain. 
Analysis of this information showed that the BIRE has an increased available yawing moment and decreased actuation times in pitch control at this flight condition. However, the BIRE variant also showed a significant decrease in available rolling moment at high yawing moments and an increase in rolling moment actuation time when compared to the baseline aircraft. It remains to be seen whether this drawback is significant, since differential tail deflections are rarely used at subsonic speeds for substantial roll control. In addition, the difference in actuation time measured approximately $500 \mathrm{~ms}$, which could be faster than the pilot control time for this flight condition. It was also shown that the BIRE variant has a lower negative correlation between roll and yaw at zero pitching moment than the baseline aircraft. This indicates that the BIRE variant experiences less adverse yaw when using solid-body tail rotations to create rolling moments, which could be a significant benefit to aircraft control properties.

Future work will focus on comparing the information obtained through the numerical lifting-line analysis given by MachUpX to that of higher-fidelity aerodynamic models. Identifying the impact of aircraft weight and the location of the center of gravity in both the baseline aircraft and the BIRE is also necessary to further detail the viability of the BIRE variant as a method of control. Finally, this work represents a static analysis of aircraft control, but the vertical tail of fighter-type aircraft is often used for stability and dynamic damping purposes. Therefore, future work will include a dynamic analysis of the aircraft to determine the feasibility of the BIRE variant with a stability augmentation system.

\section{Acknowledgments}

This work was funded by the Air Force Office of Scientific Research (AFOSR) Lab Task 20RQCOR028 with Dr. Les Lee as the program manager. This paper has been cleared for public release, Case Number:AFRL-2021-3800.

\section{References}

[1] Insinna, V., “The US Air Force's radical plan for a future fighter could field a jet in 5 years," Available athttps://www.defensenews .com/digital-show-dailies/2019/09/16/the-us-air-forces-radicalplan-for-a-future-fighter-could-field-a-jet-in-5-years/, Sep. 2019.

[2] Hunsaker, D. F., Phillips, W. F., and Joo, J. J., "Aerodynamic Shape Optimization of Morphing Wings at Multiple Flight Conditions," AIAA SciTech 2017 Forum, 2017. doi:10.2514/6.2017-1420.

[3] Simon, J., Blake, W., and Multhopp, D., “Control Concepts for a Vertical Tailless Fighter," Aircraft Design, Systems, and Operations Meeting, 1993. doi:10.2514/6.1993-4000.

[4] Myszka, D. H., Joo, J. J., and Murray, A. P., "A Pareto Front Mechanism Optimization for Controlling an Aircraft using a Bio-Inspired Rotating Empennage," Proceedings of the 2021 International Design Engineering Technical Conference, ASME, 2021.

[5] Storer, J. H., The flight of birds analyzed through slow-motion photography, 28, Cranbrook Institute of Science, 1948.

[6] Pennycuick, C., and Webbe, D., “Observations on the fulmar in Spitsbergen,” British Birds, Vol. 52, 1959, pp. 321-332.

[7] Thomas, A. L. R., "On the aerodynamics of birds' tails," Philisophical Transactions of the Royal Society B: Biological Sciences, Vol. 340, No. 1294, 1993, pp. 361-380.

[8] Hummel, D., "Aerodynamic investigations on tail effects in birds," Zeitschrift für Flugwissenschaften und Weltraumforschung, Vol. 16, No. 3, 1992, pp. 159-168.

[9] Ajanic, E., Feroskhan, M., Mintchev, S., Noca, F., and Floreano, D., "Bioinspired wing and tail morphing extends drone flight capabilities," Sci. Robot., Vol. 5, 2020, p. eabc2897.

[10] Carruthers, A. C., Thomas, A. L., and Taylor, G. K., "Automatic aeroelastic devices in the wings of a steppe eagle Aquila nipalensis," Journal of Experimental Biology, Vol. 210, No. 23, 2007, pp. 4136-4149.

[11] Oehme, H., "Die Flugsteuerung des Vogels. I," Ober flugmechanische Grundlagen, Beitr Vogelkd Leipzig, Vol. 22, 1976, pp. 58-66.

[12] Pennycuick, C. J., Mechanics of Flight, Academic Press, United States, 1975, Vol. 5, pp. 1 - 75.

[13] Parga, J. R., Reeder, M. F., Leveron, T., and Blackburn, K., "Experimental study of a micro air vehicle with a rotatable tail," Journal of aircraft, Vol. 44, No. 6, 2007, pp. 1761-1768. 
[14] Gillies, J. A., Thomas, A. L. R., and Taylor, G. K., "Soaring and manoeuvring flight of a steppe eagle Aquila nipalensis," Journal of Avian Biology, Vol. 42, No. 5, 2011. doi:10.1111/j.1600-048X.2011.05105.x.

[15] Warrick, D. R., Bundle, M. W., and Dial, K. P., "Bird Maneuvering Flight: Blurred Bodies, Clear Heads," Integrative and Comparative Biology, Vol. 42, 2002, pp. 141-148. doi:10.1093/icb/42.1.141.

[16] Oehme, H., “Die Flugsteuerung des Vogels. III,” Flug-man6ver der Kornweihe, 1976, pp. 73-82.

[17] Horton-Smith, C., The Flight of Birds, Witherby, 1938.

[18] Bilo, D., "Course Control During Flight," Perception and Motor Control in Birds, Springer, 1994, p. 21. doi:10.1007/978-3642-75869-0.

[19] Oehme, H., "Der Flug des Fahnendrongos(Dicrurus macrocercus)," Journal für Ornithologie, Vol. 106, No. 2, 1965, pp. 190-203. doi:10.1007/BF01793760.

[20] Stenfelt, G., and Ringertz, U., "Yaw Control of a Tailless Aircraft Configuration," Journal of Aircraft, Vol. 47, No. 5, 2010, pp. 1807-1811. doi:10.2514/1.C031017.

[21] "A tale of two tails: Developing an avian inspired morphing actuator for yaw control and stability," ???? URL http: //iopscience.iop.org/10.1088/1748-3190/aaa51d

[22] Plack, T., "Red Kites in Flight/Close Up,”, 2019. URL https://www . youtube. com/watch?v=3sB_-cBAUZ8

[23] Dorsett, K. M., and Mehl, D. R., “Innovative Control Effectors (ICE),” 1996, p. 410.

[24] Roetman, E., Northcraft, S., and Dawdy, J., "Innovative Control Effectors (ICE)," Tech. rep., BOEING DEFENSE AND SPACE GROUP SEATTLE WA, 1996.

[25] Hodgkinson, J., Aircraft Handling Qualities, Oxford, 1999.

[26] Moorhouse, D. J., and Woodcock, R. J., "Background information and user guide for MIL-F-8785C, military specification-flying qualities of piloted airplanes,” Tech. rep., Air Force Wright Aeronautical Labs Wright-Patterson AFB OH, 1982.

[27] Bras, M., Vale, J., Lau, F., and Suleman, A., "Flight Dynamics and Control of a Vertical Tailless Aircraft," Journal of Aeronautics I\& Aerospace Engineering, Vol. 2, No. 4, 2013, p. 1-10.

[28] Bolender, M. A., and Doman, D. B., "Method for Determination of Nonlinear Attainable Moment Sets," Journal of guidance, control, and dynamics, Vol. 27, No. 5, 2004, pp. 907-914.

[29] Durham, W. C., "Attainable Moments for the Constrained Control Allocation Problem," Journal of Guidance, Control, and Dynamics, Vol. 17, No. 6, 1994, pp. 1371-1373.

[30] Durham, W. C., "Constrained Control Allocation:Three-Moment Problem,” Journal of Guidance, Control, and Dynamics, Vol. 17, No. 2, 1994, pp. 330-336.

[31] Shaw, R., F-16 Fighting Falcon, Motorbooks International, 1996.

[32] Nguyen, L., Ogburn, M., Gilbert, W., Kibler, K., Brown, P., and Deal, P., "Simulator Study of Stall/Post-Stall Characteristics of a Fighter Airplane With Relaxed Longitudinal Static Stability,” NASA TR-1538, 1979.

[33] Conners, T., and Sims, R., "Full flight envelope direct thrust measurement on a supersonic aircraft," 34th AIAA/ASME/SAE/ASEE Joint Propulsion Conference and Exhibit, American Institute of Aeronautics and Astronautics, 1998. doi:10.2514/6.1998-3872.

[34] Reid, J. T., and Hunsaker, D. F., "A General Approach to Lifting-Line Theory, Applied to Wings with Sweep," AIAA Scitech 2020 Forum, American Institute of Aeronautics and Astronautics, 2020. doi:10.2514/6.2020-1287.

[35] Goates, C. D., and Hunsaker, D. F., "Practical Implementation of a General Numerical Lifting-Line Method," AIAA SciTech 2021 Forum, 2021, p. 0118.

[36] Phillips, W. F., and Snyder, D. O., "Modern Adaptation of Prandtl's Classic Lifting-Line Theory," Journal of Aircraft, Vol. 37, No. 4, 2000, p. 662-670. doi:10.2514/2.2649.

[37] Stevens, B. L., and Lewis, F. L., "Aircraft Control and Simulation,” Aircraft Engineering and Aerospace Technology, 2004. 
[38] Broyden, C. G., "The convergence of a class of double-rank minimization algorithms 1. general considerations," IMA Journal of Applied Mathematics, Vol. 6, No. 1, 1970, pp. 76-90.

[39] Fletcher, R., "A new approach to variable metric algorithms," The computer journal, Vol. 13, No. 3, 1970, pp. 317-322.

[40] Goldfarb, D., "A family of variable-metric methods derived by variational means," Mathematics of computation, Vol. 24, No. 109, 1970, pp. 23-26.

[41] Shanno, D. F., "Conditioning of quasi-Newton methods for function minimization," Mathematics of computation, Vol. 24, No. 111, 1970, pp. 647-656.

[42] Rockafellar, R. T., Convex analysis, Vol. 36, Princeton university press, 1970.

[43] Akkiraju, N., Edelsbrunner, H., Facello, M., Fu, P., Mucke, E., and Varela, C., "Alpha shapes: definition and software," Proceedings of the 1st international computational geometry software workshop, Vol. 63, 1995, p. 66.

[44] Delaunay, B., et al., "Sur la sphere vide," Izv. Akad. Nauk SSSR, Otdelenie Matematicheskii i Estestvennyka Nauk, Vol. 7, No. 793-800, 1934, pp. 1-2.

[45] Golias, N., and Dutton, R., "Delaunay triangulation and 3D adaptive mesh generation," Finite elements in analysis and design, Vol. 25, No. 3-4, 1997, pp. 331-341.

[46] Phillips, W. F., "Effects of Tail Dihedral on Yaw Stability," Mechanics of Flight, John Wiley I\& Sons, Inc., 2010, Chap. 5, $2^{\text {nd }}$ ed., pp. 529-547. 